\title{
EL LIBERALISMO IGUALITARIO DE JOHN RAWLS
}

\section{Imer B. FLORES}

RESUMEN: En el artículo se analiza el paradigma, tanto cognoscitivo como organizativo, de la Teoría de la Justicia de John Rawls, así como la trascendencia del pensamiento de este autor. Para tal efecto, el trabajo se divide en cinco apartados. El primero presenta el contexto de esta obra y la resonancia intelectual que ha tenido. El segundo expone la propuesta teórica de Rawls, examinando su inspiración kantiana, la crítica que hace del utilitarismo y la discusión propiamente dicha de la "justicia como imparcialidad". En esto último se incluyen aspectos como el de la sociedad bien ordenada, la concepción de la persona, la posición original y el velo de la ignorancia, los principios de la justicia, los bienes primarios, la prioridad de la libertad y, por último, el debate sobre la configuración del paradigma liberal "fundado en los derechos". El tercer apartado introduce algunas objeciones a Rawls que han sido formuladas por diversos autores desde la perspectiva del comunitarismo. El cuarto apartado examina las respuestas y concesiones de Rawls a sus críticos. Por último, el quinto apartado presenta algunas notas finales sobre el liberalismo igualitario y el porvenir de la polémica aquí reseñada.
ABSTRACT: This article analyzes the paradigm of the Theory of Justice by John Rawls, together with the perspicacity of this author's thought, from both a cognitive and an organizational viewpoint. For this purpose, the work is divided into five sections. The first presents the context of the work and its intellectual resonance. The second put forward the theoretical proposal of Rawls, examining his Kantian inspiration, his criticism of utilitarianism and a fittingly expressed discussion of "justice as impartiality". The latter covers subjects such as that of a well-organized society, the concept of the individual, the original position and the veil of ignorance, the principles of justice, primary assets, the priority of freedom and, lastly, a debate on the configuration of the liberal paradigm "founded on rights". The third section introduces some objections to Rawls which have been prepared by various authors from the point of view of communitarianism, while the fourth part examines the replies and concessions given by Rawls to his critics. Lastly, the fifth section contains some final notes on egalitarian liberalism and the future of the polemics outlined here.

1 Investigador del Instituto de Investigaciones Jurídicas de la UNAM y candidato a investigador nacional del SNI. El autor agradece a Mario Melgar Adalid y Mario Melgar Fernández fomentar el análisis y la discusión sobre la teoría de Rawls, a quienes dedica este trabajo. 
La justicia es la primera virtud de las instituciones sociales, como la verdad lo es de los sistemas de pensamiento. Una teoría, por muy atractiva y esclarecedora que sea, tiene que ser rechazada o revisada si no es verdadera; de igual modo, no importa que las leyes e instituciones estén ordenadas y sean eficientes: si son injustas han de ser reformadas o abolidas.

John Rawls, A Theory of Justice, § 1

\section{INTRODUCCIÓN}

Rechazar o revisar un pensamiento por su falsedad y reformar o abolir una institución por su injusticia son dos problemas diferentes, pero consustanciales al ser humano: la búsqueda de la verdad y la realización de la justicia. Sin embargo, ambos son unum et idem como el hilo conductor que permite a John Rawls escribir la obra más importante de las últimas décadas: A Theory of Justice. ${ }^{2}$ En menos de treinta años, es considerado un clásico al cual podemos caracterizar como la aportación más trascendental del fin de siglo para la filosofía moral y política, e incluso para la jurídica por sus contribuciones al constitucionalismo y a la teoría de la justicia.

La resonancia de este tratado ha sido incomparable, no sólo por despertar un gran interés sino también por reavivar la discusión teórica y práctica de los problemas normativos. Baste recordar la existencia de varios centenares de artículos y libros, cuya diversidad es manifiesta pues unos se preocupan directamente por los argumentos y razones de Rawls; ${ }^{3}$

2 Véase Rawls, John, A Theory of Justice, Cambridge, Massachusetts, Harvard University Press, 1971. (Hay versión en español: Teoría de la justicia, trad. de María Dolores González, México, Fondo de Cultura Económica, 1979.) (Las referencias posteriores a esta obra las haremos en el texto y entre paréntesis.)

3 Cfr. Barry, Brian, The Liberal Theory of Justice. A Critical Examination of Principal Doctrines in A Theory of Justice by John Rawls, Oxford, Clarendon Press, 1973. (Hay versión en español: La teoría liberal de la justicia. Examen crítico de las principales doctrinas de Teoría de la justicia de John Rawls, trad. de Heriberto Rubio, México, Fondo de Cultura Económica, 1993.) Norman Daniels (ed.), Reading Rawls: Critical Studies of a Theory of Justice, Nueva York, Basic Books, 1974. Gauss, G. F., "The Convergence of Rights and Utility: The Case of Rawls and Mill", Ethics, núm. 92, octubre de 1981. Haksar, Vinit, Liberty, Equality and Perfectionism, Oxford, Oxford 
algunos presentan variantes dentro del mismo paradigma liberal; ${ }^{4}$ otros promueven posturas alternativas o contrarias, como el comunitarismo; ${ }^{5} \mathrm{y}$ muchos más simplemente reflexionan sobre la magnitud del debate.

Es evidente que las defensas se multiplicaron con la polémica in crescendo. De hecho, la réplica del profesor de Harvard comenzó en consabidas respuestas a algunos de sus detractores, tanto a Lyons y Teitelman ${ }^{6}$ como a Alexander y Musgrave. ${ }^{7}$ Asimismo, en una contestación tácita a algunas interrogantes ${ }^{8}$ antes de formular una declaración expresa de las bases de su teoría, ${ }^{9}$ así como proceder a realizar un reajuste de la misma

University Press, 1979; Hare, R. M., "Rawls' Theory of Justice”, Philosophical Quarterly, vol. 23, núm. 144, 1973; Harsanyi, John C., "Can the Maximin Principle Serve as a Basis for Morality? A Critique of John Rawls' Theory”, American Political Science Review, vol. 69, núm. 2, junio de 1975; Hart, H. L. A., "Rawls on Liberty and Its Priority", University of Chicago Law Review, vol. 40, 1973. O. Höffe (ed.), Über John Rawls' Theorie der Gerechtigkeit, Frankfurt, 1977. Rae, Douglas, "Maximin Justice and an Alternative Principle of General Advantage", American Political Science Review, vol. 69, núm. 2, junio de 1975. Richards, David A. J., "Rights and Autonomy", Ethics, núm. 92, octubre de 1981; Sen, Amartya, "Rawls versus Bentham: An Axiomatic Examination of the Pure Distribution Problem", Theory and Decision, núm. 4, 1974. Sen, Amartya, "Equality of What?", The Tanner Lectures on Human Values, Stanford, Stanford University, 1980. Sneed, J. D., "Some Consequences of Rawls and Justice in Simple Economics", Synthèse, núm. 32, 1976. Wolff, Robert Paul, Understanding Rawls. A Reconstruction and Critique of A Theory of Justice, Princeton, Princeton University Press, 1977. (Hay versión en español: Para comprender a Rawls. Una reconstrucción y una crítica de Teoría de la Justicia, trad. de Marcial Suárez, México, Fondo de Cultura Económica, 1981.)

4 Cfr. Dworkin, Ronald, Taking Rights Seriously, Cambridge, Massachusetts, Harvard University Press, 1977. (Hay versión en español: Los derechos en serio, trad. de Marta Guastavino, Barcelona, Planeta-Agostini, 1993.) Nozick, Robert, Anarchy, State and Utopia, Nueva York, Basic Books, 1974. (Hay versión en español: Anarquía, Estado y utopía, trad. de Rolando Tamayo, México, Fondo de Cultura Económica, 1988.)

5 Cfr. MacIntyre, Alasdair, After Virtue. A Study in Moral Theory, Notre Dame, Notre Dame University Press, 1981; Sandel, Michael, Liberalism and the Limits of Justice, Nueva York, Cambridge University Press, 1982; Taylor, Charles, Hegel, Nueva York, Cambridge University Press, 1975; Unger, Roberto Mangabeira, Knowledge and Politics, Nueva York, Free Press, 1975. (Hay versión en español: Conocimiento y política, trad. de Leonardo Rodríguez Ozan, México, Fondo de Cultura Económica, 1985.) Walzer, Michael, Spheres of Justice. A Defense of Pluralism and Equality, Nueva York, Basic Books, 1983. (Hay versión en español: Las esferas de la justicia. Una defensa del pluralismo y la igualdad, trad. de Heriberto Rubio, México, Fondo de Cultura Económica, 1993.)

6 Rawls, John, "Reply to Lyons and Teitelman", Journal of Philosophy, LXIX, 1972.

7 Id., "Reply to Alexander and Musgrave", Quarterly Journal of Economics, 88, 1974. (Hay versión en español: "Réplica a Alexander y Musgrave", Justicia como equidad. Materiales para una teoría de la justicia, trad. de Miguel Ángel Rodilla, Madrid, Tecnos, 1986.)

8 Id., "Fairness to Goodness", Philosophical Review, vol. 84, núm. 4, 1975.

9 Id., "The Basic Structure as Subject", en A. I. Goldman y J. Kim (eds.), Values and Morals, Dordrecht, Reidel, 1978. 
en diferentes artículos; ${ }^{10}$ finalmente, como franca ampliación y revisión al reunir dichos escritos en un nuevo libro: Political Liberalism. ${ }^{11}$

Sin lugar a dudas, los alcances de Teoría de la justicia son impresionantes. Por ello, analizar o discutir sus aportaciones en forma exhaustiva puede ser no sólo una titánica labor sino también una misión imposible. Por estas razones, el presente artículo tiene el propósito de sentar las bases para identificar las líneas generales que permitan una más clara reflexión sobre la trascendencia de esta obra. Sin embargo, es imperativo aclarar que pretendemos hacer una reconstrucción de los argumentos formulados por Rawls, las objeciones presentadas por algunos de sus críticos y las réplicas - o concesiones - realizadas a sus detractores. Empero, la intención no es meramente exponer objetivamente una descripción de dicha reconstrucción sino presentar además nuestras observaciones de manera crítica, a manera de prescripción, tanto valorativa de diversos puntos de la misma como proyectiva de su futuro.

En este sentido, aunque la configuración del nuevo paradigma liberal fundado en derechos es inobjetable, su consolidación puede ser objeto de innumerables cuestionamientos. Por lo tanto, es menester proceder a la conciliación entre el liberalismo igualitario y las versiones moderadas del comunitarismo para garantizar — defender y proteger- no sólo la libertad sino también la igualdad y el pluralismo.

10 Rawls, John, "Kantian Constructivism in Moral Theory", The Journal of Philosophy, LXXVII, 1980. (Hay versión en español: "El conductivismo kantiano en la teoría moral”, Justicia como equidad. Materiales para una teoría de la justicia, cit. en nota 7.) Rawls, John, "The Basic Liberties and Their Priority”, en S. M. McMurrin (ed.), The Tanner Lectures on Human Values, vol. 3, Utah, University of Utah Press, 1982. (Hay versión en español: Sobre las libertades, trad. de Jorge Vigil Rubio, Barcelona, Paidós, Universidad Autónoma de Barcelona, 1990.) Rawls, John, "Social Unity of Primary Goods", en A. Sen et B. Williams, Utilitarianism and Beyond, Cambridge, Cambridge University Press, 1982. (Hay versión en español: "Unidad social y bienes primarios", Justicia como equidad. Materiales para una teoría de la justicia, cit. en nota 7.) Rawls, John, "Justice as Fairness: Political not Metaphysical", Philosophy and Public Affairs, vol. 14, núm. 3, 1985. Rawls, John, "The Idea of an Overlapping Consensus", Oxford Journal of Legal Studies, vol. 7, núm. I, 1987. Rawls, John, "The Priority of Right and Ideas of the Good", Philosophy and Public Affairs, vol. 17, núm. 4, 1988. Rawls, John, “Justice as Fairness. A Briefer Restatment”, manuscrito, 1990. Rawls, John, "The Idea of Public Reason", manuscrito, 1990.

11 Rawls, John, Political Liberalism, Nueva York, Columbia University Press, 1993. (Hay versión en español: Liberalismo político, trad. de Sergio René Madero Báez, México, Facultad de Derecho-Universidad Nacional Autónoma de México y Fondo de Cultura Económica, 1995.) 


\section{EL NUEVO PARADIGMA LIBERAL "RIGHTS BASED”}

Al concluir la segunda guerra mundial y durante la posguerra, el liberalismo puede ser caracterizado de muy distintas maneras, como la crítica del historicismo (Popper), la protesta contra la pesadilla totalitaria (Orwell), el pluralismo ético (Berlin), el neoevolucionismo (Hayek), y la sociología histórica (Aron); entre otras. ${ }^{12}$ Sin embargo, ninguna de estas caracterizaciones es del todo afortunada. No fue sino hasta los años setenta que el "enorme tratado" del "callado Rousseau de Harvard", "fue recibido como el nuevo evangelio de los liberales" al convertirse en la "obra magistral" que instaura verdaderamente un "nuevo paradigma liberal" denominado "rights based" ${ }^{13}$ Así, este paradigma "deontológico" o "fundado en los derechos" tiene el objetivo específico de poner "fin a la supremacía del utilitarismo" y "elaborar una concepción de la justicia para las sociedades democráticas modernas". ${ }^{14}$

El propósito de Rawls es "presentar una concepción de la justicia que generalice y lleve a un nivel más elevado de abstracción" la tradición contractual, cuyos máximos exponentes son Hobbes, Locke, Rousseau y Kant. Aclara que no debemos pensar en el contrato original como indispensable para establecer una sociedad o fundar un gobierno, sino más bien "la idea directriz es que los principios de la justicia para la estructura básica de la sociedad, son el objeto del acuerdo inicial". De esta manera, el problema consiste en precisar cuáles son los principios de justicia "que las personas libres y racionales interesadas en promover sus propios intereses aceptarían en una posición inicial de igualdad como definitorios de los términos fundamentales de su asociación" (§ 3).

12 Véase Popper, Karl R., La sociedad abierta y sus enemigos, Buenos Aires, Paidós, 1967; George Orwell, 1984, Oxford, Clarendon Press, 1984. Berlin, Isaiah, "Two Concepts of Liberty", Four Essays on Liberty, Oxford, Oxford University Press, 1969. Friedrich August von Hayek, The Constitution of Liberty, Chicago, University of Chicago Press, 1960. (Hay versión en español: Los fundamentos de la libertad, trad. de José Vicente Torrente, Madrid, Unión Editorial, 1991.) Aron, Raymond, Ensayo sobre las libertades, Madrid, Alianza Editorial, 1966.

13 Merquior, José Guilherme, Liberalismo viejo y nuevo, traducción de Stella Mastrangelo, México, Fondo de Cultura Económica, 1993, p. 183. Sobre la formulación y variantes del nuevo paradigma liberal fundado en derechos, $c f r$. Nozick, Robert, Anarchy, State and Utopia, cit. en la nota 4, y Dworkin, Ronald, Taking Rights Seriously, cit. en la nota 4.

14 Mouffé, Chantal, "El liberalismo norteamericano y sus críticos: Rawls, Taylor, Sandel, Walzer”, Estudios. Filosofía/Historia/Letras, núm. 15, invierno de 1988, pp. 98-99. 


\section{El antecedente kantiano}

La filosofía moral de Kant ${ }^{15}$ sirve de punto de partida a Rawls para desarrollar su teoría de la justicia. Al respecto, cabe mencionar algunos postulados éticos del pensador de Königsberg para comprender posteriormente su utilización por el profesor de Harvard, quien explícitamente ofrece una "interpretación kantiana" de la "posición original" y del "velo de la ignorancia" para enmendar los errores que impidieron que los principios fundamentales de la moral kantiana, además de ser universales, como los principios de la lógica, pudieran - al mismo tiempoposeer un contenido sustantivo.

Los seres humanos como entes "fenoménicos" están sujetos a las leyes empíricas de la naturaleza y dependientes de sus apetitos, deseos e inclinaciones, mientras que como agentes "nouménicos" son libres e independientes de las contingencias del mundo físico. De hecho, los principios morales de la razón práctica son: 1) autónomos —uno se los da a sí mismo-; 2) categóricos —no están condicionados a determinados fines o propósitos-; y 3) universales — válidos para todos los seres racionales-. Así, los principios fundamentales de la moral son aquellos que todos, como sujetos racionales, queremos con independencia de nuestros apetitos, deseos e inclinaciones contingentes que diferencian a unos $\mathrm{y}$ a otros. Cada ser racional quiere la misma ley que cualquier otro quiere $\mathrm{y}$, por lo tanto, esa ley moral obliga a todos por igual, porque cada uno la formula con autonomía, retoma categóricamente, y reconoce con validez universal, tal como lo consagra el celebérrimo "imperativo categórico": Obra sólo según una máxima tal que puedas querer al mismo tiempo que se torne ley universal. Por ende, es menester advertir que a partir de este principio puramente formal del razonamiento práctico, según Kant, podemos derivar principios morales sustantivos, como el renombrado principio general del derecho: Obra externamente de tal modo que el libre ejercicio de tu arbitrio pueda conciliarse con la libertad de todos según una ley universal.

15 Cfr. Kant, Immanuel, Fundamentación de la metafísica de las costumbres, trad. de Manuel García Morente, Madrid, Espasa Calpe, 1921; Crítica de la razón práctica, trad. de E. Miñana y Villasagra y Manuel García Morente, Madrid, Espasa Calpe, 1913, y La metafísica de las costumbres, trad. de Adela Cortina Orts y Jesús Conill Sancho, Barcelona, Altaya, 1993. 
Sin duda alguna, la teoría de Rawls es de inspiración kantiana por: 1) pertenecer a la tradición contractualista; 2) recuperar la concepción de seres noumenales; y 3) retomar la moral deontológica y formal. No obstante, pretende superar a Kant, quien al parecer fracasó en su intento de derivar principios morales sustantivos de principios puramente formales o cuasiformales del razonamiento práctico. Para ello, Rawls pretende liberar a la persona, a los principios de justicia y a la teoría moral de la metafísica kantiana, al redimirlos, en términos estrictamente empíricos.

\section{La crítica del utilitarismo y de otras concepciones sobre el bien}

El utilitarismo justifica la "maximización" del bienestar de la sociedad bajo el conocido principio de utilidad: "la mayor felicidad del mayor número" ( $c f r$. § 5). Aunque sea racional maximizar el interés general, no es justo si eso implica sacrificar a un cierto número de personas y a sus intereses particulares, en nombre de la utilidad de la mayoría, porque los seres humanos no pueden ser degradados a la condición de cosas para el beneficio de otros. Tal como lo prescribe el deber de considerar a todo ser humano como un fin en sí mismo y nunca como un medio. En este sentido, "lo razonable debe tener la prioridad sobre lo racional", pues la cooperación social sustenta la "prioridad de lo recto sobre el bien". Esto es, "la prioridad de un marco de derechos y libertades fundamentales sobre las diferentes concepciones del bienestar" (véase $§ 6$ y 68). A pesar de que el utilitarismo aparece como la concepción más racional del bien, reduce todo problema de la justicia a un criterio para maximizar satisfacciones, según su utilidad. De igual forma, hay otras concepciones del bien como el intuicionismo ( $c f r$. § 7) y el perfeccionismo ( $c f r$. § 50) que pretenden ser igualmente válidas, pero resultan insuficientes.

$\mathrm{El}$ intuicionismo reconoce la existencia de principios irreductibles que deben "ser sopesados unos con otros" al preguntar "qué balance es el más justo". Además, "sostiene que ya no existen criterios constructivos... que sirvan para determinar el énfasis correcto de los principios competitivos de la justicia". Cuando principios diferentes entran en competencia deben ser ponderados, según nuestras intuiciones particulares, al resolver cuál de ellos debe prevalecer en la situación específica. No obstante, "no hay... una pauta única que dé cuenta de ellos o les asigne sus valores respectivos." Así, tienen dos características: primera, consiste en una pluralidad de principios que pueden estar en conflicto; y segunda, no 
incluye un método explícito, ni reglas de prioridad para valorar estos principios entre sí. En el caso de que existan reglas de prioridad, éstas se "reducen a la trivialidad... o bien conducen a la falsedad o a la supersimplificación...” (§ 7).

El perfeccionismo se puede subdividir en dos posturas: una moderada (Aristóteles) y otra radical (Nietzsche). En ambas el principio de la perfección se erige como "el único principio de una teoría teleológica, que dirige a la sociedad a proyectar las instituciones y a definir los derechos y obligaciones de las personas, para maximizar los resultados de la excelencia humana, en el arte, la ciencia y la cultura" ( $\$ 50)$. Sin embargo, esta postura entraña un grave peligro para la libertad, porque puede imponer a priori un tipo de ser humano único y justificar las privaciones de la libertad; así como propiciar el paternalismo y respaldar el reduccionismo. De hecho, la amenaza se puede resumir en el maquiavélico: "el fin justifica los medios". Cabe recordar que la perfección tanto de los griegos como del superhombre requerían de la esclavitud y del nihilismo, respectivamente. De esta forma, Rawls concluye: "El intuicionismo no es constructivo; el perfeccionismo es inaceptable" (§ 9). Para él, es definitivo que "el punto de vista contractual ocupa una posición intermedia entre el perfeccionismo y el utilitarismo" ( $\$ 50)$. Por tanto, el contractualismo "puede servir como una concepción moral alternativa" (idem).

\section{La justicia como imparcialidad}

El antecedente de la teoría de la justicia es la noción de “justicia como imparcialidad". ${ }^{16}$ Ésta permite generalizar y llevar a un nivel más alto de abstracción la concepción tradicional del contrato social al incorporar restricciones procedimentales, basadas en razonamientos diseñados, para conducir a un acuerdo original acerca de los principios de la justicia. De hecho, Rawls afirma (\$1):

Cada persona posee una inviolabilidad fundada en la justicia que incluso el bienestar de la sociedad... no puede atropellar... la justicia niega que la pérdida de libertad para algunos sea correcta por el hecho de que un mayor bien sea

16 Véase Rawls, John, “Justice as Fairness”, The Philosophical Review, LXVII, 1958. (Hay versión en español: "Justicia como equidad", Justicia como equidad. Materiales para una teoría de la justicia, cit. en nota 7.) 
compartido por otros... No permite que los sacrificios impuestos a unos sean sobrevalorados por la mayor cantidad de ventajas disfrutadas por muchos... en una sociedad justa, las libertades de la igualdad de ciudadanía se toman como establecidas definitivamente; los derechos asegurados por la justicia no están sujetos a regateos políticos ni al cálculo de intereses sociales... Siendo las primeras virtudes de la actividad humana, la verdad y la justicia no pueden estar sujetas a transacciones.

De lo anterior se puede concluir que la estructura básica de la sociedad es el objeto primario de la justicia y el papel de ésta es esencial en la cooperación social. De hecho, una sociedad

es una asociación, más o menos autosuficiente, de personas que reconocen ciertas reglas de conducta como obligatorias en sus relaciones, y que en su mayoría actúan de acuerdo con ellas... estas reglas especifican un sistema de cooperación diseñado para promover el bien de aquellos que toman parte en él, ya que aun cuando la sociedad es una empresa cooperativa para obtener ventajas mutuas, se caracteriza típicamente tanto por un conflicto como por una identidad de intereses.

No obstante, para ello "se requiere entonces un conjunto de principios para escoger entre los diferentes arreglos sociales que determinan esta división de ventajas y para suscribir un convenio sobre las participaciones distributivas correctas". Por tanto, estos principios "proporcionan un modo para asignar derechos y deberes en las instituciones básicas de la sociedad y definen la distribución apropiada de los beneficios y las cargas de cooperación social" ( $(1)$.

De esta manera, "el objeto primario de la justicia es la estructura básica de la sociedad". Es decir, "el modo en que las instituciones sociales más importantes distribuyen los derechos y deberes fundamentales y determinan la división de las ventajas provenientes de la cooperación social" ( $(2)$. Por ello, es necesario profundizar en tres aspectos de la "justicia como imparcialidad".

\section{A. La sociedad bien ordenada}

"Una sociedad está bien ordenada no sólo cuando está diseñada para promover el bien de sus miembros, sino cuando también está efectivamente regulada por una concepción de la justicia." Esto es, "que se trata 
de una sociedad en la que: 1) cada cual acepta y sabe que los otros aceptan los mismos principios de justicia, y 2) las instituciones sociales básicas satisfacen generalmente estos principios y se sabe generalmente que lo hacen". Por supuesto, que "las sociedades existentes rara vez están... bien ordenadas, ya que usualmente está en discusión lo que es justo e injusto." A pesar de que "cada uno tiene una concepción de la justicia", todos comparten un "concepto de la justicia... especificado por el papel que tienen en común estos diferentes conjuntos de principios y concepciones". No obstante, "las instituciones son justas cuando no se hacen distinciones arbitrarias entre las personas al asignarles derechos y deberes básicos y cuando las reglas determinan un balance correcto entre pretensiones competitivas respecto a las ventajas de la vida social” (§ 1).

\section{B. La concepción de la persona}

La caracterización de la persona no meramente como animal físico - homo phaenomenon - que busca exclusivamente su bienestar sino como ser moral - homo noumenon - susceptible de acción, tanto "racional" como "razonable", es fundamental. En primer lugar, debe prevalecer la concepción de la persona como agente moral, como "personas libres e iguales bajo condiciones que son imparciales". En segundo término, "los miembros del grupo en la situación inicial son racionales y mutuamente desinteresados", pero no "egoístas". De esta forma, "la justicia como imparcialidad comienza... con la elección de los primeros principios de una concepción de justicia que habrá de regular toda la crítica y reforma subsecuente de las instituciones". Así, las personas en la situación original escogerían dos principios: 1) igualdad en la repartición de derechos y deberes básicos; y, 2) las desigualdades sociales y económicas solamente son justas si producen beneficios compensadores para todos en general, y para los miembros menos aventajados de la sociedad, en particular (véase $\S 3$ ).

Al suponer que "cada persona, después de cierta edad y dotada de la capacidad intelectual indispensable, desarrolla, bajo condiciones sociales normales, un sentido de la justicia. Adquirimos una habilidad para juzgar a las cosas como justas e injustas y para apoyar estos juicios en razones" (§ 9). De hecho, también se supone que "los grupos en la posición original son iguales, esto es, todos tienen los mismos derechos en el procedimiento para escoger principios". De este modo, es indispensable una 
condición de igualdad entre "los seres humanos en tanto que personas morales, en tanto que criaturas que tienen una concepción de lo que es bueno para ellas y que son capaces de tener un sentido de la justicia." Por eso, es menester proponer un razonamiento moral, denominado "equilibrio reflexivo", para incorporar las intuiciones que tenemos del bien y compararlas con principios más generales. Si éstos coinciden podemos avanzar, pero si no lo hacen debemos revisar nuestras intuiciones y principios, hasta que nuestros juicios coincidan por completo. Por esta razón, el equilibrio reflexivo: "Es equilibrio porque finalmente nuestros principios y juicios coinciden; y es reflexivo puesto que sabemos a qué principios se ajustan nuestros juicios reflexivos y conocemos las premisas de su derivación” (§ 4).

\section{La posición original}

La "posición original" debe servir de mediadora entre la concepción de la persona y los principios de justicia que pretendemos construir, a partir de un "status quo inicial apropiado que asegura que los acuerdos fundamentales alcanzados en ella sean imparciales". Así, la posición originaria es el resultado del "equilibrio reflexivo" y como tal "puramente hipotética". Por un lado, "representa el intento de acomodar, dentro de un esquema, tanto las condiciones filosóficas razonables sobre los principios, como los juicios que tenemos acerca de la justicia". Por otro lado, no pretende que "los principios de justicia propuestos sean verdades necesarias o derivables de tales verdades", sino que están justificados porque habría consenso sobre ellos en una situación inicial de igualdad (\$ 4).

De este modo, "el contenido del acuerdo apropiado no es ingresar en una sociedad dada o adoptar una forma dada de gobierno, sino aceptar ciertos principios morales". En este sentido, la cuestión es "determinar qué principios de la justicia serían escogidos en la posición original". De hecho, cabe señalar que para Rawls — como lo es para Kant— "la posición original no está pensada como un estado de cosas históricamente real [sino] como una situación puramente hipotética caracterizada de tal modo que conduce a cierta concepción de la justicia". No obstante, la noción de "justicia como imparcialidad" requiere que la elección se realice en una "situación hipotética de igual libertad", para lo cual es menester escoger los principios de la justicia tras un "velo de ignorancia" 
con el fin de organizar las bases que conduzcan a la cooperación social entre personas libres e iguales (véase $§ 3$ ).

\section{a. El velo de ignorancia}

Sin duda alguna, "la intención de la posición original es establecer un procedimiento equitativo según el cual cualesquiera que sean los principios convenidos, éstos sean justos". Para ello, tenemos que anular los efectos de las contingencias específicas que ponen a los seres humanos en situaciones desiguales y en tentación de explotar las circunstancias naturales y sociales en su propio provecho. Por esta razón, Rawls recurre a una condición hipotética en la cual "las partes están situadas bajo un velo de ignorancia", dicha condición es clave para garantizar la imparcialidad de los resultados deseados y posibilitar la elección unánime de una determinada concepción de la justicia (véase $\$ 24$ ).

El "velo de ignorancia" requiere de ciertas condiciones; es decir, de una situación imaginaria de imparcialidad, en la que las partes carecen de información completa y perfecta, lo cual les impone una decisión bajo incertidumbre. Así, las partes desconocen cómo las diversas alternativas afectarán sus propios casos particulares, por lo cual se ven obligados a evaluar los principios únicamente sobre la base de consideraciones generales, universales, públicas, completas y finales, porque no saben qué lugar van a ocupar, una vez que el velo haya sido levantado. De hecho, según Rawls, la noción del "velo de la ignorancia” está implícita, en la ética de Kant, en su doctrina sobre el imperativo categórico (véase $§ 40$ ). Estas restricciones pueden definir

los principios de la justicia como aquellos que aceptarían en tanto que seres iguales, en tanto que personas racionales preocupadas por promover sus intereses, siempre y cuando supieran que ninguno de ellos estaba en situación de ventaja o desventaja en virtud de contingencias sociales y naturales (§4).

\section{$b$. Los principios de justicia}

El método de constructivismo kantiano, esto es "equilibrio reflexivo" y "velo de la ignorancia", motiva a Rawls para formular "dos principios de justicia" en la "posición original": 
Primero: Cada persona ha de tener un derecho igual al esquema más extenso de libertades básicas iguales que sea compatible con un esquema semejante de libertades para los demás.

Segundo: Las desigualdades sociales y económicas habrán de ser conformadas de modo tal que cuando: a) se espere razonablemente que sean ventajosos para todos, $b$ ) se vinculen a empleos y cargos asequibles para todos.

Uno postula "el principio de libertad igual" mientras que el otro consagra tanto "la igualdad de oportunidades" como "el principio diferencial". Así, el primero pugna por la máxima e igual libertad compatible para todos y tiene prioridad sobre el segundo. En cambio, la cláusula b) acerca de la oportunidad igual de todos los miembros a realizar sus propios fines, tiene prioridad sobre la cláusula a) respecto al máximo beneficio para los miembros menos aventajados de la sociedad (véase § 11).

Este último principio consiste en una derivación del óptimo de Pareto, según el cual una distribución determinada es suficiente, cuando no es posible cambiarla sin mejorar a determinadas personas en detrimento o al empeorar, al mismo tiempo, la situación de las demás. Al respecto, "el principio diferencial" consagra la "igualdad democrática" (véase § 12) e indica que la "posición original" es una situación de incertidumbre, en donde la decisión más racional es reducir las posibles pérdidas. A este criterio de racionalidad o principio de prudencia, para decidir en situaciones de incertidumbre, Rawls lo llama "maximin" —maximum minimorum - consistente en maximizar los mínimos y no los máximos: maximizar los peores resultados y no los mejores (véase $§ 26$ ).

\section{c. Los bienes primarios}

La defensa de los dos principios de justicia y del resultado procedimental, es objeto específico de la teoría de los bienes primarios, que son los requisitos sine qua non para realizar "el plan de vida más racional a largo plazo, en circunstancias razonables". De esta forma, los bienes primarios son expectativas que pueden ser definidas simplemente como el indicador de los bienes que un individuo representativo puede esperar. De hecho,

son las cosas que se supone que un hombre racional quiere tener, además de todas las demás que pudiera querer. Cualesquiera que sean en detalle los 
planes racionales de un individuo, se supone que existen varias cosas de las que preferiría tener más que menos. Teniendo más de estas cosas, se les puede asegurar a los individuos en general que tendrán mayor éxito en la consecución de sus intenciones y en la promoción de sus fines, cualesquiera que estos fines puedan ser.

Asimismo, se presentan en amplias categorías como derechos, libertades y oportunidades, incluso ingresos y riquezas (véase $§ 15$ ).

\section{d. La prioridad de la libertad}

Rawls advierte "el problema de la prioridad", y para ello propone diversas "reglas de prioridad". Entre las cuales destaca que se debe mantener el "orden serial o léxico" de los tres principios (véase $§ 8$ ). En primer lugar, "la prioridad de la libertad" debe ser entendida como "la prioridad del principio de libertad igual sobre el segundo principio de la justicia. Ambos principios están en un orden lexicográfico, y, por tanto, las demandas de la libertad han de ser satisfechas en primer lugar. Hasta que esto no se consigue, ningún otro principio entra en juego". De este modo, "la prioridad de la libertad significa que la libertad puede ser solamente restringida en favor de la libertad en sí misma" (véase § 39). En segundo lugar, "la prioridad de la justicia sobre la eficacia y el bienestar" deriva de que "el segundo principio de la justicia es lexicográficamente anterior al principio de la eficacia, y al que maximiza la suma de ventajas; y la igualdad de oportunidades es anterior al principio de la diferencia." En tercer lugar, "todos los bienes sociales primarios - libertad, igualdad de oportunidades, renta, riqueza, y las bases de respeto mutuo-, han de ser distribuidos de un modo igual, a menos que una distribución desigual de uno o de todos estos bienes redunde en un beneficio de los menos aventajados." Finalmente, sobre estas bases, reformula los "dos principios de la justicia" (véase $\S 46$ ).

Primer principio: Cada persona ha de tener un derecho igual al más amplio sistema total de libertades básicas, compatible con un sistema de libertad para todos.

Segundo principio: Las desigualdades económicas y sociales han de ser estructuradas de manera que sea para: a) mayor beneficio de los menos aventajados, de acuerdo con un principio de ahorro justo, y b) unido 
a que los cargos y las funciones sean asequibles a todos, bajo condiciones de justa igualdad de oportunidades.

\section{La trascendencia de la Teoría de la justicia}

La amplia significación de este tratado es fruto de su extensa y notoria repercusión dentro de la filosofía jurídica, moral y política, e incluso en el constitucionalismo y en la teoría de la justicia. Especialmente, por los productos de la copiosa y profunda resonancia de la misma, como podemos percibir de la infinidad de críticas y discusiones de las cuales es el tema central. A continuación, procedemos a mostrar algunos de los impactos críticos de la obra y a presentar algunas variantes del nuevo paradigma liberal.

Por una parte, dentro de los exámenes exhaustivos de las principales doctrinas de Rawls, destacan sendos libros: uno de Brian Barry y el otro de Robert Paul Wolff. Barry afirma que "Se trata sencillamente de una obra que ha de ser tomada en cuenta de modo prioritario por quienes en el futuro se propongan abordar cualquiera de los temas considerados en ella y aspiren a ganarse la atención de la comunidad académica." ${ }^{17}$ No obstante, denuncia que está plagado tanto de incoherencias e inconsistencias en la argumentación como de redundancias y reiteraciones inútiles. Su principal observación es que al aislar algunos aspectos del liberalismo - como la propiedad privada - se puede introducir un principio de distribución con implicaciones igualitarias, compatible con el socialismo, pero abiertamente contrario a su antítesis: el propio liberalismo. Por ello, reitera que la verdadera: "esencia del liberalismo es la concepción de una sociedad constituida por unidades independientes y autónomas, que cooperan sólo cuando los términos de la cooperación fomentan los fines de cada una de las partes".

Asimismo, Wolff reitera que hay graves y numerosas confusiones en este importante pero desconcertante libro. Su modelo es brillante, original y poderoso al pretender demostrar o, por lo menos, esbozar la demostración de un "teorema". Sin embargo, es muy cuestionable que sus objetivos se hayan cumplido, porque puede resultar demasiado abstracto e insatisfactorio a pesar de múltiples advertencias, complicaciones y mati-

17 Barry, Brian, La teoría liberal de la justicia..., cit. en la nota 3, p. 9.

18 Ibidem, p. 172. 
ces. De este modo, se le puede situar "históricamente en la tradición de la economía política liberal utópica" y caracterizar "como una apología filosófica con un sello igualitario del capitalismo liberal del Estado de bienestar." 19 Empero, afirma: "El poder de la teoría consiste en la fuerza creadora y en la imaginación de ese recurso, mediante el cual Rawls esperaba esquivar la estéril disputa entre intuicionismo y utilitarismo." 20

Al respecto, es menester hacer tres observaciones sobre las críticas anteriores. Primera, existe una tensión evidente sobre si la postura de Rawls que podemos caracterizar como "liberalismo igualitario" es genuinamente liberal o no, puesto que puede ser compatible tanto con el socialismo como con el liberalismo del Estado benefactor. Segunda, como consecuencia de lo anterior, aunque la teoría pretende defender la neutralidad, es un manifiesto ideológico, pero esta afirmación no se debe enfocar a considerar la teoría y sus consecuencias como falsas sino a tener presente que: “es ideología... prescripción disfrazada de análisis de valor neutral". ${ }^{21}$ Tercera, una de las grandes objeciones a la teoría, se puede rastrear en su inspiración kantiana y en el intento de derivar conclusiones sustantivas de principios formales o meramente procedimentales. De hecho,

La enorme complejidad y la capacidad imaginativa de Rawls nos muestran que el fracaso se debe, no a ningún tipo de insuficiencias de ejecución, sino más bien a la inherente debilidad de toda esa tradición de filosofía política de la que Teoría de la justicia es, tal vez, el producto más distinguido. ${ }^{22}$

En términos generales, el común denominador de las críticas se refieren a la metodología empleada por Rawls, ya sea por apoyar su construcción en nuestras intuiciones; por el dudoso valor justificatorio de un contrato hipotético realizado en una posición original imaginaria; por la presuposición de que las partes tendrían una actitud tan conservadora como para adoptar el maximin; por la nebulosa procedencia de los principios de justicia, de la prioridad de la libertad y demás reglas de prio-

19 Wolff, Robert Paul, Para comprender a Rawls..., cit. en la nota 3, p. 175. (El énfasis es original.)

20 Ibidem, p. 187.

21 Ibidem, p. 175.

22 Ibidem, p. 187. Sobre la trascendencia de la obra de Kant, véase Wolff, Robert Paul, The Autonomy of Reason; A Commentary on Kant's Grounwork of the Metaphysic of Morals, Nueva York, Harper \& Row, 1973. 
ridad, que los presentan como extrañamente incompletos; entre muchas otras cuestiones que son el blanco de diferentes ataques. ${ }^{23}$

Por otra parte, a pesar de los embates anteriores, la aceptación de algunas de las principales tesis es clara. Existen dos autores que, dentro del propio paradigma liberal, presentan sus versiones mediante algunas precisiones sobre los alcances y las limitaciones tanto teóricas como prácticas del pensamiento de Rawls. Estas dos variantes las representan: Ronald Dworkin y Robert Nozick.

Por un lado, Dworkin señala que "El profesor Rawls, de Harvard... ha publicado un libro sobre la justicia, abstracto y complejo, que ningún abogado constitucionalista puede dejar de leer." ${ }^{24}$ Así, procede a formular algunas observaciones sobre el papel que desempeña la "posición original" en el proceso de justificación de los dos principios de justicia. Primera, "la metodología de Rawls presupone el modelo constructivo" mientras que "el modelo natural no constituye base firme para la técnica del equilibrio". Segunda, "la teoría profunda que respalda la posición original debe ser algún tipo de teoría basada en derechos... en vez de ser una teoría de los otros dos tipos", ya sea fundada en los deberes o en los objetivos. Tercera, "El derecho básico de la teoría profunda de Rawls debe ser... un derecho abstracto, es decir, que no sea derecho a ningún objetivo individual determinado. Dentro de los conceptos ordinarios de la teoría política, hay dos candidatos a desempeñar este papel": la libertad y la igualdad. Así, "la posición original" protege las libertades básicas en interés del derecho a la igualdad. ${ }^{25}$ Por supuesto que ambas - libertad e igualdad - desafortunadamente se encuentran en conflicto constante. De hecho, tanto el "liberalismo" como el "buen gobierno" consisten en el mejor "compromiso" entre estos dos "principios constitutivos" o "ideales contendientes". ${ }^{26}$

El paradigma fundado en los derechos es recogido por Dworkin para contraponer al tradicional "modelo de reglas" un "modelo de princi-

23 Véase Hare, R. M., "Rawls' Theory of Justice” y Hart, H. L. A., "Rawls on Liberty and Its Priority", cit. en la nota 3.

24 Dworkin, Ronald, Taking Rights Seriously, cit. en la nota 4, p. 149.

25 Ibidem, pp. 150-183.

26 Dworkin, Ronald, A Matter of Principle, Cambridge, Massachusetts, Harvard University Press, 1985, pp. 188-204. 
pios". A partir de la distinción entre nomos y theseis, ${ }^{27}$ establece la diferenciación entre principle y policy. Dicha distinción es fundamental en la interpretación y aplicación del derecho, pues el modelo basado en principios - y orientado por políticas públicas- es hoy por hoy, el estilo dominante de análisis jurídico e imprescindible para comprender el desarrollo del constitucionalismo moderno ${ }^{28}$ No obstante, reconoce que la única crítica que prevalece es que el diseño de la "posición original" no es moralmente neutro: $:^{29}$

Las instituciones y disposiciones políticas que... serían las elegidas por hombres que se encontrasen en la posición original, no son más que formas idealizadas de las que actualmente se encuentran en vigor en los Estados Unidos. Es decir, son las instituciones de la democracia constitucional liberal. Los críticos infieren que los supuestos fundamentales de la teoría de Rawls deben ser, pues, los supuestos del liberalismo clásico... y que la posición original... debe ser de alguna manera la encarnación de tales supuestos. Por consiguiente, la justicia en cuanto equidad les parece, en su totalidad, una racionalización especialmente sutil del statu quo político...

\section{Por otro lado, Nozick advierte que}

A Theory of Justice es un trabajo vigoroso, profundo, sutil, amplio, sistemático dentro de la filosofía política y la filosofía moral... Es una fuente de ideas esclarecedoras, integradas conjuntamente en un todo perfecto. Ahora los filósofos políticos tienen que trabajar según la teoría de Rawls, o bien, explicar por qué no lo hacen. ${ }^{30}$

Procura demostrar que podemos llegar a una concepción de justicia diametralmente opuesta, a pesar de partir de una posición similar, como la formulada por Locke. De esta forma, no sólo "justifica el Estado

27 Cfr. Friedrich August von Hayek, Law, Legislation and Liberty. A Nueva Statement of the Liberal Principles of Justice and Political Economy, Chicago, University of Chicago Press, 1979. (Hay versión en español: Derecho, legislación y libertad. Una nueva formulación de los principios liberales de la justicia y de la economía política, trad. de Luis Reig Albiol, Madrid, Unión Editorial, 1985.)

28 Véase Dworkin, Ronald, Taking Rights Seriously, cit. en la nota 4, y A Matter of Principle, cit. en la nota 26. Véase, también, Dworkin, Ronald, Law's Empire, Cambridge, Massachusetts, Harvard University Press, 1986.

29 Dworkin, Ronald, Taking Rights Seriously, cit. en la nota 4, p. 182.

30 Nozick, Robert, Anarchy, State and Utopia, cit. en la nota 4, p. 183. 
mínimo" - limitado a unas cuantas funciones de protección - sino también "sostiene que ningún Estado más extenso puede justificarse" - porque precisamente violaría los derechos individuales-. De hecho, sustenta el nuevo paradigma basado en derechos al reconocer que "los individuos tienen derechos, y hay cosas que ninguna persona o grupo puede hacerles sin violar los derechos". ${ }^{31}$

No obstante, su premisa fundamental "El Estado mínimo es el Estado más extenso que se puede justificar", ${ }^{32}$ implica una doble, además de muy severa, crítica para Rawls. ${ }^{33}$ En primer lugar, el Estado mínimo se encuentra en contraposición con cualquier Estado más extenso, como es la especie de Estado liberal democrático, propugnado por el ideal rawlsiano. En segundo término, lo anterior implica que el Estado mínimo se debe limitar a defender el orden; por lo cual rechaza cualquier otro tipo de función distributiva. Así, objeta que Rawls esté concentrado exclusivamente en el problema de la distribución de bienes, al olvidar la producción de los mismos y, peor aún, desconocer que las cosas pertenecen a alguien mediante títulos especiales, como la propiedad, mismos que no se pueden ignorar sin violar los derechos individuales: ${ }^{34}$

Si las cosas cayeran del cielo como maná, y nadie tuviera ningún derecho especial a alguna porción de él, y no cayera ningún maná a menos que todos acordaran una distribución particular y, de alguna manera, la cantidad variara según la distribución, entonces es verosímil sostener que las personas colocadas de tal manera que no pudieran lanzar amenazas o hacer ofrecimientos para recibir porciones especialmente grandes, acordarían la regla del principio de diferencia de distribución. Pero ¿es éste el modelo apropiado para pensar sobre cómo deben ser distribuidas las cosas que las personas producen?

Evidentemente, para Nozick no. El principio diferencial es distributivo, no productivo; además de violatorio de los derechos individuales que precisamente son el objeto de una teoría fundada en los derechos. Sin embargo, tanto Dworkin como Nozick coinciden en que el nuevo paradigma liberal se debe basar o fundar en los derechos, pero ambos difieren de los alcances y limitaciones de la Teoría de la justicia. El segundo

31 Ibidem, pp. IX-XIV.

32 Ibidem, p. 149.

33 Ibidem, pp. 183-231.

34 Ibidem, p. 198. 
rechaza el ideal político rawlsiano como un Estado mayor al mínimo, además de ser distributivo; mientras que el primero acepta que el pensamiento de Rawls constituye la piedra angular del mejor compromiso para solucionar el conflicto entre libertad e igualdad, pero que definitivamente no podemos considerar como neutral.

\section{CRÍTICA AL LIBERALISMO IGUALITARIO DE RAWLS}

Antes de proceder a una crítica más exhaustiva del liberalismo igualitario es conveniente mencionar que para Paulette Dieterlen los tres grandes méritos de la teoría de la justicia de Rawls son: 1) rescatar el pensamiento contractualista; 2) conciliar dos principios que parecían pertenecientes a dos tradiciones distintas: del liberalismo la idea de la libertad y del socialismo la de igualdad; y, 3) reconciliar dos tradiciones que dentro del pensamiento liberal se veían como antagónicas: la libertad de los modernos o libertades cívicas y la libertad de los antiguos o libertades políticas. ${ }^{35}$ Lo anterior sirve al propósito de adelantar cuáles son sus principales aportaciones y como éstas seguramente serán, explícita o implícitamente, el objeto de los embates de sus detractores. "Pero los críticos del liberalismo tienen ahora la responsabilidad de demostrar que estos argumentos son erróneos". ${ }^{36}$

En síntesis, presentamos las objeciones de los críticos del liberalismo, en general, y del liberalismo igualitario, en particular, concretamente, a partir del punto de vista del comunitarismo. Esta crítica ataca no sólo a Rawls sino también a la filosofía misma del liberalismo, en razón de su individualismo, al denunciar una "concepción ahistórica, asocial y descarnada del sujeto, que implica la idea de un individuo dotado de derechos naturales anteriores a la sociedad, y rechaza la tesis de la prioridad del derecho sobre el bien". ${ }^{37}$ A continuación, vamos a presentar brevemente los argumentos de cada uno de los principales críticos comunitarios y en el próximo apartado a precisar qué representa el comunitarismo como bloque frente al liberalismo igualitario de Rawls.

35 Dieterlen, Paulette, "La filosofía política de John Rawls", Revista Mexicana de Ciencias Políticas y Sociales, nueva época, año XXXVII, núm. 150, octubre-diciembre de 1992, p. 108.

36 Dworkin, Ronald, Taking Rights Seriously, cit. en la nota 4, p. 183.

37 Mouffé, Chantal, cit. en la nota 14, p. 101. 


\section{Alasdair MacIntyre: comunitarismo y virtudes aristotélicas}

MacIntyre presenta —en After Virtue - una "denuncia profética", llena de malos augurios respecto al futuro, como invitación a un retorno a la tradición moral de las virtudes aristotélicas. En este sentido, reprocha que la teoría de la justicia no deja ningún lugar a la noción fundamental de "mérito". Considera que esto se debe sobre todo a la concepción de una sociedad compuesta por individuos, cuyos intereses son definidos con anterioridad e independencia de la construcción de cualquier lazo moral entre ellos. Por lo tanto, la noción de mérito solamente tiene sentido en el contexto de una sociedad cuyo lazo originario es una comprensión compartida, tanto del bien de la comunidad como del individuo, y donde éstos identifican sus intereses fundamentales con referencia a dichos bienes. Por esta razón, rechaza tanto la noción de derechos como el intento de fundarlos en la racionalidad de la ilustración. ${ }^{38}$

$\mathrm{Al}$ respecto, sostiene:

La mejor razón para afirmar de un modo tajante que no existen tales derechos es precisamente del mismo tipo que la mejor que tenemos para afirmar que no hay brujas, o la mejor razón que poseemos para afirmar que no hay unicornios: el fracaso de todos los intentos de dar buenas razones para creer que tales derechos existan.

En relación con la falta de atención sobre los "méritos", cabe mencionar que para Rawls la valoración de éstos queda supeditada a lo que se disponga en los diferentes arreglos institucionales, bajo la inspiración de los dos principios de justicia. Así, el profesor de Harvard, reformula la idea de merecimiento al preferir la noción de "expectativas legítimas" para garantizar, dentro del contexto de la justicia como imparcialidad, unos mínimos considerados innegociables por el consenso político básico. ${ }^{39}$

\section{Michael Sandel: liberalismo y los límites de la justicia}

Sandel realiza —en Liberalism and the Limits of Justice - un análisis minucioso de la teoría de Rawls, con el objeto de probar sus inconsis-

38 Véase MacIntyre, Alasdair, After Virtue..., cit. en la nota 5, pp. 169-189, 227-237 y 238-245.

39 Rawls, John, "The Idea of an Overlapping Consensus", cit. en la nota 10, p. 14. 
tencias. En primer lugar, ataca la tesis de la prioridad del derecho sobre el bien y la concepción de persona que implica. El liberalismo deontológico exige una concepción de la justicia que no presuponga ninguna idea particular del bien para servir de marco general con la finalidad de que en su interior sean posibles diferentes concepciones del bien. En este sentido, por exigencias lógicas el derecho debe ser anterior al bien, pero ello supondría como necesario que el sujeto sin ataduras existiera independientemente de sus fines e intenciones. Por consiguiente, su tesis central es que esto implica una concepción "descarnada" del sujeto, la cual es necesaria para que el derecho pueda tener prioridad sobre el bien. ${ }^{40}$ Sin embargo, para él, es contradictoria con los principios de justicia que pretende sustentar, en general, y con el de diferencia, en particular, que sin duda requiere un compromiso constitutivo, al concluir: "No podemos ser personas para quienes la justicia es primaria y también personas para quienes el principio de diferencia es un principio de justicia." ${ }^{41} \mathrm{Al}$ respecto, consideramos muy atinado y pertinente el argumento en contra del sujeto descarnado y, en este sentido, la clara contradicción de pretender fundar una teoría distributiva sobre las premisas del individualismo liberal. Así, tanto Hayek como Nozick son más congruentes, pero precisamente este es uno de los puntos en que A Theory of Justice pretende superar la filosofía liberal clásica y radical, al desarrollar un liberalismo moderado de corte igualitario.

Con lo anterior promueve que Rawls no logre justificar, de manera convincente, la primacía de la justicia ni la prioridad del derecho sobre el bien, pero eso no le permite concluir que eso prueba la superioridad de una política del bien común sobre la defensa de los derechos, puesto que no podemos definir el derecho antes que el bien, ya que solamente a través de nuestra participación en una comunidad que define al bien, podemos tener un sentido del derecho y de la justicia. De hecho, la más grande incongruencia del liberalismo rawlsiano estriba en presentarse como una solución política, sin compromisos epistemológicos ni metafísicos, aunque en realidad está plagado de ellos. Asimismo, cabe hacer notar que la prioridad del derecho sobre el bien, para los liberales de tipo kantiano, significa que no podemos sacrificar los derechos individuales

40 Véase Sandel, Michael, Liberalism and the Limits of Justice, cit. en la nota 5, pp. 175-183.

41 Ibidem, p. 178. 
en nombre del bienestar general, ni derivar los principios de justicia de una concepción particular del bien. ${ }^{42}$

\section{Charles Taylor: atomismo y la dialéctica hegeliana}

Taylor enfatiza - en su libro sobre Hegel y en otros escritos- que la visión liberal del sujeto es "atomística", al afirmar el carácter autosuficiente del individuo frente a la comunidad. En esta concepción está el origen de la destrucción de la vida pública, a través de un vicioso individualismo, que constituye un empobrecimiento en relación con la noción aristotélica del zoon politikon. Además, considera que a partir de la participación en una comunidad de lenguaje y discurso mutuos podemos desarrollar la racionalidad y el ser humano convertirse en un sujeto moral capaz de buscar el bien. Por tanto, para el profesor canadiense no puede haber prioridad del derecho sobre el bien, al demostrar lo absurdo de partir de la prioridad de los derechos individuales con el fin de deducir de ellos el contexto social, puesto que el individuo moderno y sus derechos son el resultado de un complejo y largo proceso histórico. También, sugiere que la postura de Kant - y cualquier otra concepción que se funde en él- tiende a ser abstracta. Por ello prefiere a Hegel, quien propone que la política tiene y debe tener un contenido concreto, producto de la praxis y de su dialéctica misma. ${ }^{43}$

\section{Roberto Mangabeira Unger: liberalismo y superliberalismo}

Unger precisa —en Knowledge and Politics - las ideas que determinan y limitan las posibilidades de nuestro pensamiento:

El liberalismo debe ser visto como una sola pieza, no justamente como un juego de doctrinas acerca de la disposición de poder y riqueza, sino como una concepción metafísica de la mente y de la sociedad. Solamente entonces su verdadera naturaleza puede ser entendida, y su imperio secreto destronado. ${ }^{44}$

42 Ibidem, p. 156.

43 Véase Taylor, Charles, Hegel, cit. en la nota 5, pp. 187-210.

44 Unger, Roberto Mangabeira, Knowledge and Politics, cit. en la nota 5, pp. 5-6. 
En este sentido, su crítica procede a presentar las "antinomias del liberalismo" en búsqueda de una "alternativa a la doctrina liberal". Por un lado, entre las antinomias destacan los conflictos entre teoría y práctica, entre razón y deseo, y entre regla y valor. Por otro lado, sostiene que el "superliberalismo" debe empujar

las premisas liberales sobre Estado y sociedad, sobre libertad y dependencia y ejercicio del poder de las relaciones sociales con la voluntad, hasta el punto en el cual ellos se funden dentro de una ambición mayor, la construcción de un mundo social menos ajeno al yo que puede siempre violar las reglas generativas de su propia construcción mental o social y poner otras reglas y otras construcciones en su lugar. ${ }^{45}$

Por ende: "Para rehacer la vida social en la imagen de la política liberal es necesario, entre otras cosas, cambiar la concepción liberal y la práctica de la política." ${ }^{46}$

\section{Michael Walzer: pluralismo e igualdad}

Por último, Walzer sustenta —en Spheres of Justice. A Defense of Pluralism and Equality - un comunitarismo moderado que no está en oposición con los ideales políticos del liberalismo. De hecho, su proyecto consiste en defender la tradición liberal democrática mediante la protección del pluralismo y de la igualdad. Sostiene que ningún pensador puede desprenderse de los lazos con su comunidad a fin de poder descubrir verdades supuestamente universales. Por el contrario debe asumir plenamente su condición de miembro de una comunidad particular, a la cual debe interpretar para sus conciudadanos. Si denuncia el racionalismo de la Ilustración y propone realzar conceptos como comunidad y tradición, es necesario para así defender el ideal democrático de manera más efectiva.

Por esta razón, critica la postura epistemológica y metodológica de Rawls. Sin embargo, está de acuerdo en la prioridad de la justicia y en la idea de que las sociedades modernas están caracterizadas por la institucionalización de la libertad e igualdad. Su teoría pluralista de la justicia

45 Unger, Roberto Mangabeira, The Critical Legal Studies Movement, Cambridge, Massachusetts, Harvard University Press, 1986, p. 41.

46 Ibidem, p. 42. 
pretende la realización de la "igualdad compleja" ${ }^{47}$ En este sentido, advierte que comúnmente la idea de igualdad parte de un modelo simple, que tiende a igualar lo más posible a las personas en situación global, pero ello implica necesariamente no sólo una intervención constante del Estado sino también abre la puerta a posturas totalitarias. Por eso, lo requerido es que los diferentes bienes sean distribuidos, no de manera uniforme, sino en función de una diversidad de criterios que reflejen la diversidad de bienes y de significaciones que le son atribuidas. Así, la justicia no es solamente cuestión de interpretación y aplicación de criterios de distribución, sino de distinciones y fronteras entre las diferentes esferas. Lo esencial es que ningún bien pueda servir de medio de dominación, así como evitar la concentración de cualquier forma de poder en unas cuantas manos. Por lo cual, la perspectiva adoptada sugiere criticar el individualismo liberal y sus presupuestos metodológicos, pero conservar y enriquecer el pluralismo del mismo, al pensar en la justicia sin buscar un punto de vista universal y sin elaborar principios generales válidos para todas las sociedades.

\section{RÉPLICA A SUS CRÍTICOS}

Cabe precisar qué debemos entender por comunitarismo y cuál es la polémica con Rawls. En principio, comprende una corriente del pensamiento moral y político en la cual coinciden algunos críticos de la modernidad nacida de la Ilustración, que se oponen tanto a la democracia liberal como a la social. Hay quienes, como MacIntyre, ${ }^{48}$ consideran que el proyecto ilustrado de la modernidad ha fracasado al privar de identidad al individuo y a la comunidad de significado común: "sin un marco teleológico todo el proyecto completo de moralidad es incomprensible". ${ }^{49}$ Asimismo, juzgan que la moralidad ilustrada es la mayor superstición de la modernidad, al pretender sobre la base de la racionalidad ser tanto neutral como universal. ${ }^{50}$

47 Véase Walzer, Michael, Spheres of Justice..., cit. en la nota 5, p. 316.

48 Véase MacIntyre, Alasdair, After Virtue..., cit. en la nota 5, pp. 49-59.

49 Ibidem, p. 53.

50 Véase MacIntyre, Alasdair, Three Rival Versions of Moral Enquiry, Notre Dame, Notre Dame University Press, 1990, pp. 170-195. 
En diversas ocasiones se les etiqueta como "premodernos" — por su nostalgia al pasado - y en otras como "posmodernos" — por su odio al presente y por su amor a un futuro incierto-. En este sentido, las críticas de MacIntyre y Sandel conducen a un callejón sin salida, al rechazar la modernidad y pretender regresar a lo premoderno. En cambio, las de Taylor, Unger y Walzer aunque parecen aceptar varios aportes del liberalismo, no es completamente antimoderna pero en definitiva tampoco es moderna, sugiere explícita o implícitamente una transición hacia lo posmoderno, mediante la revisión de muchas de nuestras categorías vigentes. De esta manera, la crítica a Rawls se puede caracterizar como una crítica al proyecto moderno de la Ilustración desde lo premoderno hasta lo posmoderno. Por lo cual, frecuentemente las objeciones se enfocan a Kant y a otros filósofos de la Ilustración como Locke y Rousseau, desde las perspectivas de Aristóteles y Maquiavelo; San Agustín y Santo Tomás; Hegel y Nietzche, e incluso Marx.

En este sentido, por definición, el "comunitarismo" hace referencia a la prioridad de la comunidad sobre el individuo, por ello está en contraposición frente al "individualismo". Por esta razón, el primero tiende a identificar al segundo como el rasgo más propio del liberalismo político. Asimismo, también se opone al "universalismo", porque este último pretende que hay una única respuesta transcultural e institucional válida para todas las sociedades.

Para Walzer ${ }^{51}$ el comunitarismo aparece como una señal de alarma que se dispara para tratar de corregir algunos excesos intermitentes que aparecen inevitablemente con el liberalismo. Resume la critica comunitaria en dos argumentos: 1) caracterizar al liberalismo como un individualismo asocial; y, 2) presentar las antinomias entre la teoría liberal y su práctica. No obstante, reconoce que ambos argumentos son mutuamente inconsistentes, pero parcialmente correctos.

La crítica al primero, relativo a la caracterización del liberalismo y a la vertiente igualitaria de Rawls como un "individualismo asocial", es acertada en el sentido de que la teoría de la justicia enfatiza al individuo y le da prioridad sobre la comunidad, aunque no necesariamente debemos considerarlos seres asociales, ajenos por completo a la sociedad. La fuerza de la "posición original" requiere que éstos sean moralmente autóno-

51 Véase Walzer, Michael, "The Communitarian Critique of Liberalism”, Political Theory, vol. 18, núm. 1, 1990, pp. 6-23. 
mos e independientes unos de otros, pero una vez que se han fijado las bases de la cooperación social, definitivamente no pueden permanecer de esta manera, porque el principio de diferencia requiere de individuos con algún grado de sociabilidad. Esta crítica sirve como alerta para que el liberalismo trate de evitar los efectos extremos, no sólo del individualismo sino también del comunitarismo.

Con relación al segundo, relativo a las antinomias del liberalismo, la crítica es parcialmente correcta, porque en muchos sentidos es inconsistente. En principio, gran parte de estas observaciones se refieren a cuestiones metodológicas y las menos a aspectos sustantivos. De ahí que la revisión que Rawls hizo de su teoría, pone mayor énfasis en la metodología, sin pretender modificar sino más bien ampliar los contenidos y la exposición de su obra principal.

Con esa orientación procede a la justificación — tanto de la adopción como de las consecuencias- de la "estructura básica" de la sociedad como el objeto primario de los principios de justicia al manifestar expresamente sus implicaciones: 1) las partes contratantes son "personas morales libres e iguales"; 2) "el contenido del acuerdo son los primeros principios que han de regular la estructura básica"; 3) la perspectiva kantiana da cuenta de "la naturaleza profundamente social de las relaciones humanas"; y, 4) la "justicia procedimental pura" permite transferir "la imparcialidad de las circunstancias... a los principios reconocidos”. Así, estos fundamentos "encarnan una forma ideal para la estructura básica a la luz de la cual han de juzgarse los procesos institucionales y reajustarse continuamente los resultados acumulados de las transacciones individuales". ${ }^{2}$ De ese modo, "la estructura básica configura el modo en que el sistema social produce y reproduce a lo largo del tiempo una cierta forma de cultura". 53

En segundo término, ofrece una reinterpretación de Kant que le permita, según él, “desprender la estructura de la doctrina kantiana de sus bases de idealismo trascendental y darle una interpretación procedimental por medio de la construcción de la posición original" para dotarle de una estructura empírica y evitar cualquier objeción de idealismo. ${ }^{54}$ Intenta presentar no sólo el "constructivismo kantiano" sino también el reajuste

52 Véase Rawls, John, “The Basic Structure as Subject”, cit. en la nota 9, pp. 47-48.

53 Ibidem, p. 55.

54 Ibidem, pp. 66-67. 
de la justificación teórica de su modelo al sustentar "una concepción particular de la persona" que, como agente de construcción racional, puede especificar mediante acuerdos "unos primeros principios realizables de justicia". ${ }^{55}$ De hecho, el gran mérito de la posición original es "incorporar la justicia procedimental pura", porque el acuerdo producido es justo, sea cual fuera, ya que "no existe un criterio independiente de justicia" sino que lo justo se define por el resultado del procedimiento mismo. $^{56}$

De este modo, a partir de una determinada concepción de persona de inspiración kantiana y de su noción de justicia, Rawls reconoce el conflicto entre dos tradiciones de pensamiento, una asociada con Locke mientras que la otra con Rousseau, a las cuales homogeneizaba dentro del contexto de la teoría del contrato social. ${ }^{57}$ Por esa razón, pretende reconciliar no sólo las exigencias de libertad e igualdad sino también las libertades civiles y las políticas, al resolver el conflicto por armonización interna de ambas, ya que están incluidas en el concepto mismo de persona moral, al "articular una concepción pública de la justicia que todos puedan vivir tanto respecto de su persona como de su relación con la sociedad", dicha concepción se justifica por "su congruencia con nuestra más profunda comprensión de nosotros mismos y de nuestras aspiraciones". ${ }^{58}$

Asimismo, Rawls elabora la distinción entre autonomía racional " $r a$ tional" y autonomía plena "reasonable" para reconciliar el egoísmo y el sentido moral. Lo razonable presupone y subordina a lo racional, porque el primero define "los términos equitativos de la cooperación" aceptados por todos, pero sin el segundo no cabe cooperación social alguna. De este modo, en la posición original los dos principios de justicia son construidos a partir de la justicia como imparcialidad, cuyo contenido es razonable para la estructura básica de una sociedad bien ordenada. ${ }^{59}$

A continuación, procede a vincular "construcción" y "objetividad" al desarrollar y matizar la visión constructivista de la objetividad, en contraposición a la tradicional identificación entre objetividad y verdad, para concluir que los dos principios son objetivos, aunque no necesariamente verdaderos. Sin duda, "son los principios más razonables para nosotros,

55 Véase Rawls, John, “Kantian Constructivism in Moral Theory”, cit. en la nota 10, p. 520.

56 Ibidem, p. 523.

57 Ibidem, p. 519.

58 Ibidem, pp. 517-519.

59 Ibidem, pp. 528-530. 
dada nuestra concepción de la persona como libre e igual, y en cuanto miembros plenamente cooperativos de una sociedad democrática”, pero no independientes de nuestro punto de partida, ni tampoco pretenden ser "verdaderos en todos los mundos posibles". De esta manera, Rawls sostiene que la objetividad de los principios consiste no en que sean "verdaderos" sino en que sean "razonables", es decir racionalmente justificados. $^{60}$

Los anteriores retoques contribuyen a mejorar la teoría, tanto en su justificación como en su metodología, al incrementar su coherencia interna por las explicaciones concretas que ofrece, mediante la reinterpretación constructivista de Kant que le facilita, a la inversa, asignar "cierta primacía a lo social: esto es, el primer objeto de la justicia es la estructura básica de la sociedad, y los ciudadanos tienen que llegar en primer lugar a un entendimiento público sobre una concepción de la justicia aplicable a este objeto". ${ }^{61}$ No obstante, también es necesario insistir en las "libertades básicas y su prioridad"; y detectar la falta de "unidad social" de los ciudadanos en torno al acuerdo marco que define los "bienes primarios". ${ }^{2}$

Sostiene que las personas deben compartir un concepto de justicia aunque sus concepciones sean distintas. La objeción puede ser relativa y simple: la imposibilidad de determinar cuáles son los valores compartidos. Al respecto, sugiere que los valores implícitos en la cultura y en las instituciones de una sociedad democrática, se toman como un hecho y están relacionados, por ejemplo, tanto con las "condiciones sociales e históricas" como con los "gobiernos constitucionales" y las "economías... de mercado". ${ }^{63}$ Es imperioso recordar que la obra de Rawls es un intento de repensar las bases teóricas y prácticas de la "estructura básica de un régimen constitucional democrático" o "de una democracia constitucional moderna", con el fin de ofrecer "una base más segura y aceptable a los principios constitucionales" como son "los derechos y las libertades básicas"; así como las "instituciones políticas, sociales y económicas". ${ }^{64}$ También, mediante la concepción "de la sociedad como un

60 Ibidem, pp. 554-572.

61 Ibidem, pp. 552-553.

62 Cfr. Rawls, John, "The Basic Liberties and Their Priority" y "Social Unity of Primary Goods", cit. en la nota 10.

63 Rawls, John, "Justice as Fairness: Political not Metaphysical”, cit. en la nota 10, p. 225.

64 Ibidem, pp. 224-226. 
sistema equitativo de cooperación entre personas libres e iguales" ${ }^{65}$ pretende resolver las críticas del "individualismo asocial". La cooperación social requiere de un conjunto de reglas públicamente reconocidas y un conjunto de procedimientos aceptados por los miembros de la cooperación, los cuales deben estar en condiciones imparciales, para que al cooperar unos con otros, todos puedan realizar su concepción del bien. ${ }^{66}$

Por estas razones, Rawls pretende que su teoría no se debe basar en argumentos o razones teóricas sino desde un punto de vista práctico: político y social. Por consiguiente, según él, "las pretensiones de la justicia como imparcialidad, en cuanto que es una concepción política, son prácticas y no metafísicas o epistemológicas". En este sentido, no se presenta como una concepción que sea verdadera, sino como una concepción que puede servir de base para el entendimiento informado y voluntario entre los ciudadanos, considerados personas libres e iguales. ${ }^{67}$

Los problemas que detecta en las sociedades modernas son la falta de unidad social de los ciudadanos en torno a un acuerdo-marco que fije los elementos constitucionales esenciales. Para ello propone, como Habermas, que la tarea práctica de la filosofía política es una tarea práctica: asegurar la cohesión social duradera y estable entre los ciudadanos de la sociedad pluralista del presente y del futuro, mediante la búsqueda argumentada de un consenso muy amplio que haga posible un régimen constitucional justo: una democracia deliberativa. ${ }^{68}$

Además, rechaza la visión teleológica de MacIntyre porque es una concepción moral comprehensiva del bien, contraria a las sociedades modernas por las consecuencias totalitarias que conduce la negación sistemática de las libertades básicas y a la eliminación del pluralismo, en

65 Ibidem, p. 231.

66 Ibidem, p. 232.

67 Ibidem, p. 230.

68 Rawls, John, "The Idea of an Overlapping Consensus", cit. en la nota 10, p. 24, y, cfr. Habermas, Jürgen, Between Facts and Norms. Contributions to a Discourse Theory of Law and Democracy, trad. de William Rehg, Cambridge, Massachusetts, The MIT Press, 1996. (Hay versión en español: Facticidad y validez. Sobre el derecho y el Estado democrático de derecho en términos de teoría del discurso, trad. de Manuel Jiménez Redondo, Madrid, Editorial Trotta, 1998.) Sobre la polémica posterior entre Habermas y Rawls, véase, Habermas, Jürgen, "Reconciliation through the Public Use of Reason: Remarks on John Rawls's Political Liberalism”, trad. de Ciaran Cronin, y John Rawls, "Reply to Habermas", The Journal of Philosophy, vol. XCII, núm. 3, marzo de 1995. (Hay versión en español: "Reconciliación mediante el uso público de la razón”, y "Réplica a Habermas", en Jürgen Habermas et John Rawls, Debate sobre el liberalismo político, trad. de Gerard Vilar Roca, Barcelona, Ediciones Paidós, 1998.) 
nombre de la uniformidad de la comunidad. ${ }^{69}$ A partir de eso, los arreglos constitucionales no fijan todas las expectativas legítimas, pero sí los mínimos considerados no negociables por el consenso político básico. Al respecto, Rawls distingue entre dos clases de asuntos: los que no se pueden someter a votación porque afectan a derechos constitucionales prefijados, y los que pueden ser debatidos y modificados con arreglo a circunstancias concretas. $^{70}$

En relación con la insistencia de Sandel, sobre la imposibilidad de justificar la prioridad del derecho sobre el bien, Rawls se vio forzado a ampliar y reiterar su postura al defender la "prioridad de los derechos", a partir de un concepto de justicia y la promoción de las diferentes "ideas del bien". ${ }^{71}$ En este sentido, no es imprescindible eliminar o evitar las concepciones del bien, lo cual es además imposible, pues las ideas tienen que ser políticas. Es decir, "tienen que estar adaptadas para satisfacer las restricciones impuestas por la concepción política de la justicia y encajar en el espacio que ella permite". ${ }^{72}$ De hecho, alude a un procedimiento equitativo y - a su decir - neutral para decidir entre las pretensiones en conflicto. $^{73}$

Por esta razón, insiste en que la "justicia como imparcialidad" es una propuesta teórico-política de justicia sin pretensiones epistemológicas ni metafísicas, pero que conserva la dimensión normativa que corresponde a las concepciones morales. Al respecto, cabe distinguir entre "concepciones generales-comprehensivas" y "concepciones políticas de justicia". ${ }^{74}$ La primera es general si se presenta como igualmente aplicable a todo tipo de sujetos y comprehensiva si es aplicable a todas las dimensiones de la vida humana; mientras que la segunda, la cual adopta en su teoría está caracterizada por: 1) elaborar una concepción moral para un sujeto específico, "la estructura básica de una sociedad democrática"; 2) aceptar esta noción no presupone ninguna doctrina comprehensiva concreta; y 3) formular ciertas ideas fundamentales implícitas en la cultura política y pública de una sociedad democrática. ${ }^{75}$ Por lo anterior, una

69 Rawls, John, “The Idea of an Overlapping Consensus", cit. en la nota 10, p. 10.

70 Ibidem, p. 14.

71 Véase Rawls, John, “The Priority of Right and Ideas of the Good”, cit. en la nota 10, pp. 251-276.

72 Ibidem, p. 271.

73 Ibidem, p. 261.

74 Ibidem, pp. 252 y ss. 
democracia no tiene objetivos ni fines últimos sino que los fines constitucionalmente especificados de la sociedad deben caer bajo una concepción política de justicia. ${ }^{76}$

Cabe reiterar que para el liberalismo no puede existir una única concepción de la eudaimonia — es decir, del bienestar - que pueda ser impuesta a todos, sino que cada uno debe tener la posibilidad de buscar su felicidad como mejor le parezca: fijar a sí mismo sus propios objetivos y tratar de realizarlos a su manera. Así, Rawls pretende defender el pluralismo liberal que requiere no imponer una concepción del bienestar y un plan de vida particular, sino respetar la moral individual para organizar su vida como mejor les plazca. De hecho, todo lo anterior reitera la importancia del paradigma fundado en los derechos y que los principios de justicia no puedan privilegiar ninguna concepción particular del bien, porque esto permite conciliar tanto libertad e igualdad como libertades cívicas y políticas.

\section{A MODO DE CONCLUSIÓN: EL FUTURO DEL DEBATE}

Rawls al recaracterizar - como política y no metafísica - su concepción de la "justicia como imparcialidad" comete el gran error de reducir la fuerza de la misma, pero su reformulación también tiene algunos aciertos. Sin duda, su construcción está plagada de compromisos tanto ideológicos como epistemológicos, los cuales además de ser políticos son metafísicos. Por ello, no puede pretender borrar de un gomazo, de la noche a la mañana, todas las implicaciones metafísicas de su construcción. Empero, este estratagema le permite evadir dos críticas. Por un lado, al defender una concepción política e ideológica —no metafísica ni epistemológica - de la "justicia como imparcialidad", ésta no tiene por qué ser una doctrina verdadera sino simplemente una construcción objetiva aunque no sea por completo neutral. Por otro lado, al atacar cualquier "concepción general-comprehensiva" mediante su "concepción política de justicia", convierte al acusador en acusado, y viceversa.

Sin duda, la teoría de Rawls debe ser agnóstica en términos de moral, pero no lo es ni puede serlo en lo político, porque reafirma los principios

75 Rawls, John, “Justice as Fairness. A Briefer Restatment”, cit. en la nota 10, p. 21.

76 Id., "The Idea of Public Reason", cit. en la nota 10, pp. 16-17. 
políticos de libertad e igualdad. Por lo tanto, los críticos comunitarios están autorizados para cuestionar la prioridad del derecho sobre el bien, pero no están legitimados para exigir que deben abandonar el pluralismo liberal o el liberalismo basado en los derechos, dado que eso es lo que precisamente caracteriza a un régimen liberal democrático. De hecho, no hay razones de peso para eliminar el pluralismo por la fuerza, porque la unidad social es posible por un consenso solapante en torno a una concepción política de lo justo, a pesar de la diversidad o de la falta de uniformidad.

Por tanto, el futuro de la polémica parece centrarse en la conciliación del liberalismo de corte igualitario de Rawls y las versiones moderadas de comunitarismo, cuando éstas se sustentan en aquél mediante la defensa y el reconocimiento de la igualdad y del pluralismo. Sin embargo, todavía quedan latentes muchas tensiones que hay que resolver: compatibilizar realmente libertad e igualdad, así como libertad civil o negativa y libertad política o positiva; complementar al ser humano fenómeno con el nóumeno, lo racional con lo razonable, la razón teórica con la razón práctica, lo físico con lo moral, el "yo" como individuo con el "yo" como miembro de la comunidad; y, sobre todo, revisar nuestras categorías vigentes, como absoluto-relativo, objetivo-subjetivo, universal/general-particular, porque la concepción de la "justicia como imparcialidad" puede ser tanto política como metafísica, sin que esto sea detrimento para la búsqueda de la verdad y la realización de la justicia.

Finalmente, para concluir, podemos parafrasear a MacIntyre para decir de Rawls, así como de su aportación a la filosofía moral y política, lo que aquél opina de Kant y de la ética: ${ }^{77}$ Rawls se ubica en uno de los grandes hitos divisorios de la historia de la filosofía moral y política. Quizá para la mayoría de los autores posteriores, incluso para muchos que conscientemente son antirawlsianos, la filosofía moral y política se define como tema en términos rawlsianos.

77 Cfr. MacIntyre, Alasdair, Historia de la ética, trad. de Roberto Juan Walton, Barcelona, Paidós, 1991, p. 185. 


\section{BIBLIOGRAFÍA}

ARON, Raymond, Ensayo sobre las libertades, Madrid, Alianza Editorial, 1966. (Título original: Essai sur les libertés, 1965.)

BARRY, Brian, La teoría liberal de la justicia. Examen crítico de las principales doctrinas de Teoría de la justicia de John Rawls, traducción de Heriberto Rubio, México, Fondo de Cultura Económica, 1993. (Título original: The Liberal Theory of Justice. A Critical Examination of Principal Doctrines in A Theory of Justice by John Rawls, Oxford, Clarendon Press, 1973.)

BERLIN, Isaiah, "Two Concepts of Liberty", Four Essays on Liberty, Oxford, Oxford University Press, 1969. (Publicación original de 1958.).

DANIEls, Norman (ed.), Reading Rawls: Critical Studies of a Theory of Justice, Nueva York, Basic Books, 1974.

DIETERLEN, Paulette, "La filosofía política de John Rawls", Revista Mexicana de Ciencias Políticas y Sociales, nueva época, año XXXVII, núm. 150, octubre-diciembre de 1992.

DWORKIN, Ronald, A Matter of Principle, Cambridge, Massachusetts, Harvard University Press, 1985.

Press, 1986.

—, Taking Rights Seriously, Cambridge, Massachusetts, Harvard University Press, 1977. (Versión en español: Los derechos en serio, traducción de Marta Guastavino, Barcelona, Planeta-Agostini, 1993.) GAuss, G. F., "The Convergence of Rights and Utility: The Case of Rawls and Mill", Ethics, núm. 92, octubre de 1981.

HABERMAS, Jürgen, Between Facts and Norms. Contributions to a Discourse Theory of Law and Democracy, traducción de William Rehg, Cambridge, Massachusetts, The MIT Press, 1996. (Versión en español: Facticidad y validez. Sobre el derecho y el Estado democrático de derecho en términos de teoría del discurso, traducción de Manuel Jiménez Redondo, Madrid, Editorial Trotta, 1998.) (Título original: Faktizität und Geltung. Beiträge zur Duskurstheorie des Rechts und des demokratischen Rechtsstaats, Frankfurt, Suhrkamp, 1992.)

, "Reconciliation through the Public Use of Reason: Remarks on John Rawls's Political Liberalism”, traducción de Ciaran Cronin, The Journal of Philosophy, vol. XCII, núm. 3, marzo de 1995. (Versión en 
español: "Reconciliación mediante el uso público de la razón”, en Jürgen Habermas y John Rawls, Debate sobre el liberalismo político, traducción de Gerard Vilar Roca, Barcelona, Ediciones Paidós, 1998.) (Título original: "Politischer Liberalismus -Eine Auseinandersetzung mit Rawls", en Die Einbeziehung des Anderen, Frankfurt, Suhrkamp, 1996.)

HAKSAR, Vinit, Liberty, Equality and Perfectionism, Oxford, Oxford University Press, 1979.

HARE, R. M., "Rawls' Theory of Justice”, Philosophical Quarterly, vol. 23, núm. 144, 1973.

HART, H. L. A., "Rawls on Liberty and Its Priority", University of Chicago Law Review, vol. 40, 1973.

HARSANYI, John C., "Can the Maximin Principle Serve as a Basis for Morality? A Critique of John Rawls' Theory", American Political Science Review, vol. 69, núm. 2, junio de 1975.

HAYEK, Friedrich August von, The Constitution of Liberty, Chicago, University of Chicago Press, 1960. (Versión en español: Los fundamentos de la libertad, traducción de José Vicente Torrente, Madrid, Unión Editorial, 1991.)

Principles of Justice and Political Economy, Chicago, University of Chicago Press, 1979. (Versión en español: Derecho, legislación y libertad. Una nueva formulación de los principios liberales de la justicia y de la economía política, traducción de Luis Reig Albiol, Madrid, Unión Editorial, 1985.)

HÖFFE, O. (ed.), Über John Rawls' Theorie der Gerechtigkeit, Frankfurt, 1977.

KANT, Immanuel, Crítica de la razón práctica, traducción de E. Miñana y Villasagra y Manuel García Morente, Madrid, Espasa Calpe, 1913. (Título original: Kritik der Praktischen Vernunft, 1788.)

- Fundamentación de la metafísica de las costumbres, traducción de Manuel García Morente, Madrid, Espasa Calpe, 1921. (Título original: Grundlegung zur Metaphysik der Sitten, 1785.)

, La metafísica de las costumbres, traducción de Adela Cortina Orts y Jesús Conill Sancho, Barcelona, Altaya, 1993. (Título original: Metaphysik der Sitten, 1797.)

MACINTYRE, Alasdair, After Virtue. A Study in Moral Theory, Notre Dame, Notre Dame University Press, 1981. 
, Historia de la ética, traducción de Roberto Juan Walton, Barce-

lona, Paidós, 1991. (Título original: A Short History of Ethics, Nueva York, MacMillan, 1966.)

- - Three Rival Versions of Moral Enquiry, Notre Dame, Notre Dame University Press, 1990.

MERQUIOR, José Guilherme, Liberalismo viejo y nuevo, traducción de Stella Mastrangelo, México, Fondo de Cultura Económica, 1993. (Título original: Liberalism. Old and New, Boston, MacMillan, 1991.)

MOUFFÉ, Chantal, "El liberalismo norteamericano y sus críticos: Rawls, Taylor, Sandel, Walzer”, Estudios. Filosofía/Historia/Letras, núm. 15, invierno de 1988.

NozICK, Robert, Anarchy, State and Utopia, Nueva York, Basic Books, 1974. (Versión en español: Anarquía, Estado y utopía, traducción de Rolando Tamayo, México, Fondo de Cultura Económica, 1988.)

ORWELl, George, 1984, Oxford, Clarendon Press, 1984. (Publicación original de 1949.)

POPPER, Karl, La sociedad abierta y sus enemigos, Buenos Aires, Paidós, 1967. (Título original: The Open Society and Its Enemies, 1945.)

RAE, Douglas, "Maximin Justice and an Alternative Principle of General Advantage”, American Political Science Review, vol. 69, núm. 2, junio de 1975.

RAWLS, John, A Theory of Justice, Cambridge, Massachusetts, Harvard University Press, 1971. (Versión en español: Teoría de la justicia, traducción de María Dolores González, México, Fondo de Cultura Económica, 1979.)

_, "Fairness to Goodness", Philosophical Review, vol. 84, núm. 4, 1975.

, “Justice as Fairness. A Briefer Restatment", manuscrito, 1990a . , "Justice as Fairness", The Philosophical Review, LXVII, 1958. (Versión en español: "Justicia como equidad", Justicia como equidad. Materiales para una teoría de la justicia, traducción de Miguel Ángel Rodilla, Madrid, Tecnos, 1986.)

1972.

"Reply to Lyons and Teitelman", Journal of Philosophy, 69,

, "Kantian Constructivism in Moral Theory", The Journal of Philosophy, LXXVII, 1980. (Versión en español: "El conductivismo kantiano en la teoría moral" en Justicia como equidad. Materiales para 
una teoría de la justicia, traducción de Miguel Ángel Rodilla, Madrid, Tecnos, 1986.)

, Political Liberalism, Nueva York, Columbia University Press, 1993. (Versión en español: Liberalismo político, traducción de Sergio René Madero Báez, México, Facultad de Derecho-Universidad Nacional Autónoma de México, Fondo de Cultura Económica, 1995.)

, "Reply to Alexander and Musgrave", Quarterly Journal of Economics, 88, 1974. (Versión en español: "Réplica a Alexander y Musgrave", Justicia como equidad. Materiales para una teoría de la justicia, traducción de Miguel Ángel Rodilla, Madrid, Tecnos, 1986.) , "Reply to Habermas", The Journal of Philosophy, vol. XCII, núm. 3, marzo de 1995. (Versión en español: "Réplica a Habermas", en Jürgen Habermas y John Rawls, Debate sobre el liberalismo político, traducción de Gerard Vilar Roca, Barcelona, Ediciones Paidós, 1998.)

, "Social Unity of Primary Goods", en A. Sen et B. Williams, Utilitarianism and Beyond, Cambridge, Cambridge University Press, 1982. (Versión en español: "Unidad social y bienes primarios", Justicia como equidad. Materiales para una teoría de la justicia, traducción de Miguel Ángel Rodilla, Madrid, Tecnos, 1986.)

"The Basic Liberties and Their Priority", en S. M. McMurrin (ed.), The Tanner Lectures on Human Values, vol. 3, Utah, University of Utah Press, 1982. (Versión en español: Sobre las libertades, traducción de Jorge Vigil Rubio, Barcelona, Paidós, Universidad Autónoma de Barcelona, 1990.)

, "The Basic Structure as Subject", en A. I. Goldman y J. Kim (eds.), Values and Morals, Dordrecht, Reidel, 1978.

_- "Justice as Fairness: Political not Metaphysical", Philosophy and Public Affairs, vol. 14, núm. 3, 1985.

"The Idea of an Overlapping Consensus", Oxford Journal of Legal Studies, vol. 7, núm. I, 1987.

"The Idea of Public Reason", manuscrito, 1990".

, "The Priority of Right and Ideas of the Good", Philosophy and Public Affairs, vol. 17, núm. 4, 1988.

RichaRDS, David A. J., "Rights and Autonomy", Ethics, núm. 92, octubre de 1981.

SANDEL, Michael, Liberalism and the Limits of Justice, Nueva York, Cambridge University Press, 1982. 
SEN, Amartya, "Equality of What?", The Tanner Lectures on Human Values, Stanford, Stanford University, 1980.

, "Rawls versus Bentham: An Axiomatic Examination of the Pure Distribution Problem", Theory and Decision, núm. 4, 1974.

y Williams, Bernard, Utilitarianism and Beyond, Cambridge, Cambridge University Press, 1982.

SNEED, J. D., "Some Consequences of Rawls an Justice in Simple Economics", Synthèse, núm. 32, 1976.

TAYLOR, Charles, Hegel, Nueva York, Cambridge University Press, 1975.

Philosophy and the Human Sciences: Philosophical Papers, II, Nueva York, Cambridge University Press, 1985. 1990.

UnGER, Roberto Mangabeira, Knowledge and Politics, Nueva York, Free Press, 1975. (Versión en español: Conocimiento y política, traducción de Leonardo Rodríguez Ozan, México, Fondo de Cultura Económica, 1985.)

- The Critical Legal Studies Movement, Cambridge, Massachusetts, Harvard University Press, 1986.

WALZER, Michael, Spheres of Justice. A Defense of Pluralism and Equality, Nueva York, Basic Books, 1983. (Versión en español: Las esferas de la justicia. Una defensa del pluralismo y la igualdad, traducción de Heriberto Rubio, México, Fondo de Cultura Económica, 1993.)

, "The Communitarian Critique of Liberalism", Political Theory, vol. 18, núm. 1, 1990.

WOLFF, Robert Paul, The Autonomy of Reason; A Commentary on Kant's Grounwork of the Metaphysic of Morals, Nueva York, Harper \& Row, 1973.

Para comprender a Rawls. Una reconstrucción y una crítica de Teoría de la Justicia, traducción de Marcial Suárez, México, Fondo de Cultura Económica, 1981. (Título original: Understanding Rawls. A Reconstruction and Critique of A Theory of Justice, Princeton, Princeton University Press, 1977.) 